\title{
A EDUCAÇÃO AMBIENTAL COMO FERRAMENTA DE ANÁLISE DA REALIDADE SOCIOAMBIENTAL DA BACIA DO RIO BOTAS: ESTUDO DE CASO NO CIEP AURÉLIO BUARQUE DE HOLANDA
}

\author{
Yasmin Ribeiro Molinari Mello \\ Graduada em Geografia e Mestra em Geografia pela Universidade Federal Rural do Rio de Janeiro (PPGGEO- \\ UFRRJ) e ex. Bolsista CAPES \\ mello.yrm@gmail.com \\ Clézio dos Santos \\ Prof .Adjunto III do Instituto Multidisciplinar da Universidade Federal Rural do Rio de Janeiro e do Programa de \\ Pós-Graduação em Geografia (PPGGEO-UFRRJ), Jovem Cientista do Nosso Estado - FAPERJ e Pesquisador \\ Universal - CNPq \\ cleziogeo@yahoo.com.br
}

\begin{abstract}
RESUMO
O presente artigo aborda as problemáticas hidrológicas do município de Nova lguaçu/RJ, especificamente do Canal Maxambomba, tributário do Rio Botas. Busca-se contextualizar as ações antrópicas que intervém na dinâmica natural fluvial, promovendo a tomada de consciência ambiental por parte da população local por meio da escola, com o estudo crítico e reflexivo de tais problemas a partir do conceito de Lugar, enfatizando o uso deste conceito nas práticas escolares no ensino de Geografia, auxiliando a transposição didática dos conteúdos científicos, aproximando a realidade e experiências locais dos estudantes dos conteúdos escolares. A análise focou no processo de urbanização da região, enfatizando as obras de saneamento da baixada fluminense, as quais modificaram drasticamente a dinâmica fluvial da região. Para as atividades realizadas no CIEP Aurélio Buarque de Holanda foram utilizadas notícias de jornais, a observação do Canal Maxambomba, identificando seus principais problemas e propondo possíveis soluções. Foram identificados problemas como a poluição do rio com descarte irregular do lixo e o lançamento de esgoto. $O$ assoreamento do rio, o entupimento de galerias pluviais e a retirada da mata ciliar. Como soluções, a coleta seletiva do lixo, criação de áreas verdes, o saneamento básico e a realização de ações coletivas da comunidade.
\end{abstract}

Palavras-chave: Problemática Hidrológica. Baixada Fluminense. Escola.

\section{ENVIRONMENTAL EDUCATION AS A TOOL FOR THE ANALYSIS OF THE SOCIO-ENVIRONMENTAL REALITY OF THE BOTAS RIVER BASIN: CASE STUDY IN CIEP AURÉLIO BUARQUE DE HOLANDA}

\begin{abstract}
This article deals with the hydrological problems of the municipality of Nova Iguaçu / RJ, specifically the Canal Maxambomba, tributary of the Rio Botas. It seeks to contextualize the anthropic actions that intervene in the natural fluvial dynamics, promoting the environmental awareness on the part of the local population through the school, with the critical and reflective study of such problems from the concept of Place, emphasizing the use of this concept in the school practices in the teaching of Geography, helping the didactic transposition of the scientific contents, bringing the reality and local experiences of the students of the school contents. The analysis focused on the process of urbanization of the region, emphasizing the sanitation works of the Fluminense lowland, which drastically changed the region's river dynamics. For the activities carried out at CIEP Aurélio Buarque de Holanda newspaper news items were used, the observation of the Canal Maxambomba, identifying its main problems and proposing possible solutions. Problems have been identified such as river pollution with irregular garbage disposal and sewage disposal. The silting of the river, the clogging of rain gutters and the removal of the riparian forest. As solutions, the selective collection of garbage, creation of green areas, basic sanitation and collective community action.
\end{abstract}

Keywords: Hydrological Problems. Baixada Fluminense. School. 


\section{INTRODUÇÃO}

A transformação do espaço geográfico através da aplicação e aprimoramento das técnicas possibilitou a sociedade a criação de cidades e consequentemente ao estabelecimento de uma cultura urbana, que em seus princípios não levou em consideração as dinâmicas do meio natural ao qual se encontrava originalmente. Tais intervenções acabaram por trazer a sociedade urbana sérios problemas socioambientais, principalmente no que diz respeito a relação com a água. No decorrer da história muitos corpos d'água foram dragados, tiveram seus cursos modificados, foram utilizados como ponto de despejo de esgoto e lixo.

Desta forma, estes corpos d'água, que não foram preservados , acabaram por se tornar um problema urbano de grande relevância, principalmente nas áreas de saúde, assistência social, educacional e meio ambiente. Pois os mesmos se tornaram fontes de proliferação de transmissores de doenças, suas margens foram ocupadas em sua maioria pela população de baixa renda, assim, é de grande importância a atuação das escolas no fomento da educação ambiental, no sentido de uma criar uma tomada de consciência na percepção da dinâmica e vivência em ambientes de bacias hidrográficas.

Neste sentido, o lugar que atualmente conhecemos como o Município de Nova Iguaçu, no Estado do Rio de Janeiro, é frequentemente atingido por problemas hidrológicos, como enchentes, alagamentos e em proporções maiores, as inundações. Estes que são mais frequentes em períodos de grande precipitação pluviométrica, como nos meses de verão. Mas, afinal, porque estes fenômenos acontecem? Os mesmos podem ser caracterizados pelas intervenções humanas realizadas no meio natural? São fenômenos unicamente naturais, onde a nossa sociedade apenas sofre com as consequências?

$\mathrm{Na}$ realidade para se compreender o que ocorre em Nova Iguaçu devemos entender os processos e dinâmicas fluviais naturais, bem como, quais e como foram realizadas as modificações antrópicas sobre este meio natural. Não podemos esquecer que a sociedade se articula com a dinâmica natural, são interdependentes. Como podemos observar, estes problemas hidrológicos que ocorrem no meio urbano nos levam a refletir sobre a relação da nossa sociedade com a natureza, suas ações modificando o meio natural e remodelando o espaço geográfico. O município de Nova Iguaçu através de sua carga histórica, dos seus diversos momentos distintos no espaço-tempo, sua população sempre esteve em constante interação com esta dinâmica hidrológica, estabelecendo toda uma vivência e costumes locais para se conviver com estas questões.

Diante disso, esta temática já se faz presente nas vivências dos estudantes de Nova Iguaçu, ou seja, já se faz pertencente ao seu lugar. Além disso, os mesmos possuem uma carga histórica acumulada de diversas gerações em suas famílias, que em muito podem contribuir para o entendimento destes problemas hidrológicos. Dentro do ambiente escolar a Geografia poderá contribuir em muito para a interpretação e compreensão destas questões, devido a sua peculiaridade de articulação das interações sociais e naturais. Com efeito, para se compreender a relação homem-natureza é necessário que todas as áreas da ciência geográfica estejam conectadas.

Como nos mostra Suertegaray (2003), a Geografia surge oficialmente como ciência no final do Século $\mathrm{XIX}$. Este momento histórico é caracterizado pelo florescer de vários ramos, áreas cada vez mais específicas dentro das principais ciências. Entre elas podemos destacar a Geologia, a Geomorfologia e a Ecologia. Porém, essa especificidade dos diferentes ramos das ciências trouxe a tona um dos principais debates existentes hoje na ciência geográfica, a separação entre Geografia Humana e Geografia Física.

Esta separação entre uma Geografia com cunho voltado apenas para o social e uma Geografia voltada apenas para os aspectos geológicos, geomorfológicos, pedológicos etc., são levados em consideração, se torna cada vez menos significativa diante das necessidades de pesquisa da atualidade. Exemplos destas necessidades são observadas em diversas situações, inclusive rotineiras para muitas pessoas.

Dentre essas situações podemos citar algumas que se relacionam com problemas que enfrentamos, como por exemplo: a questão das moradias em áreas de encostas (com a desigualdade social, os riscos de deslizamentos, o desmatamento entre outros.), a degradação de bacias hidrográficas em áreas urbanas (com a poluição pelo lançamento de esgoto, dejetos industriais, moradias em áreas de proteção permanente - APPs etc.), o descarte irregular do lixo em área urbana (com a penetração do chorume no lençol freático, a proliferação de doenças, o trabalho infantil nos lixões, entre outros.), as atividades agropecuárias (com o uso de pesticidas, sementes transgênicas, uso intensivo do solo, agricultura monocultora, pisoteio do gado, desmatamento etc.)

$\begin{array}{llllll}\text { Caminhos de Geografia } & \text { Uberlândia - MG } & \text { v. 19, n. } 68 & \text { Dez/2018 } & \text { p. 116-131 } & \text { Página } 117\end{array}$


Todavia, também temos pesquisas que buscam aprofundar e desenvolver cada vez mais as possíveis soluções para estes e outros problemas de nossa sociedade, como por exemplo: o planejamento urbano, o incentivo e aprofundamento da formação de professores e profissionais qualificados, políticas de reflorestamento, criação de unidades de conservação, fomento a educação ambiental, criação de aterros sanitários, cooperativas de reciclagem, uso da agricultura orgânica, entre tantas outras.

Diante disto percebe-se que, tanto os problemas, quanto as soluções, exigem que a pesquisa geográfica seja vista em associação do natural com o social. É necessário o conhecimento de aspectos como os geomorfológicos, os geológicos, os climáticos, os pedológicos, os biogeográficos, além é claro do conhecimento das profundas relações socioeconômicas, culturais e socioambientais que modelam a nossa sociedade.

Neste sentido, a concepção de Geografia apresentada no artigo trabalha com o conceito de lugar como uma forma de aproximar os conteúdos científicos da realidade dos estudantes, materializando as informações no espaço de vivência dos mesmos. Para tal abordagem, foi realizado um estudo de caso através da execução de um projeto escolar com estudantes do $6^{\circ}$ ano do ensino fundamental, no Centro Integrado de Educação Básica - CIEP Aurélio Buarque de Holanda (Figura 01). O projeto teve como objeto central de análise as problemáticas hidrológicas urbanas existentes no recorte espacial do presente artigo.

Figura 01: CIEP 317 - Aurélio Buarque de Holanda

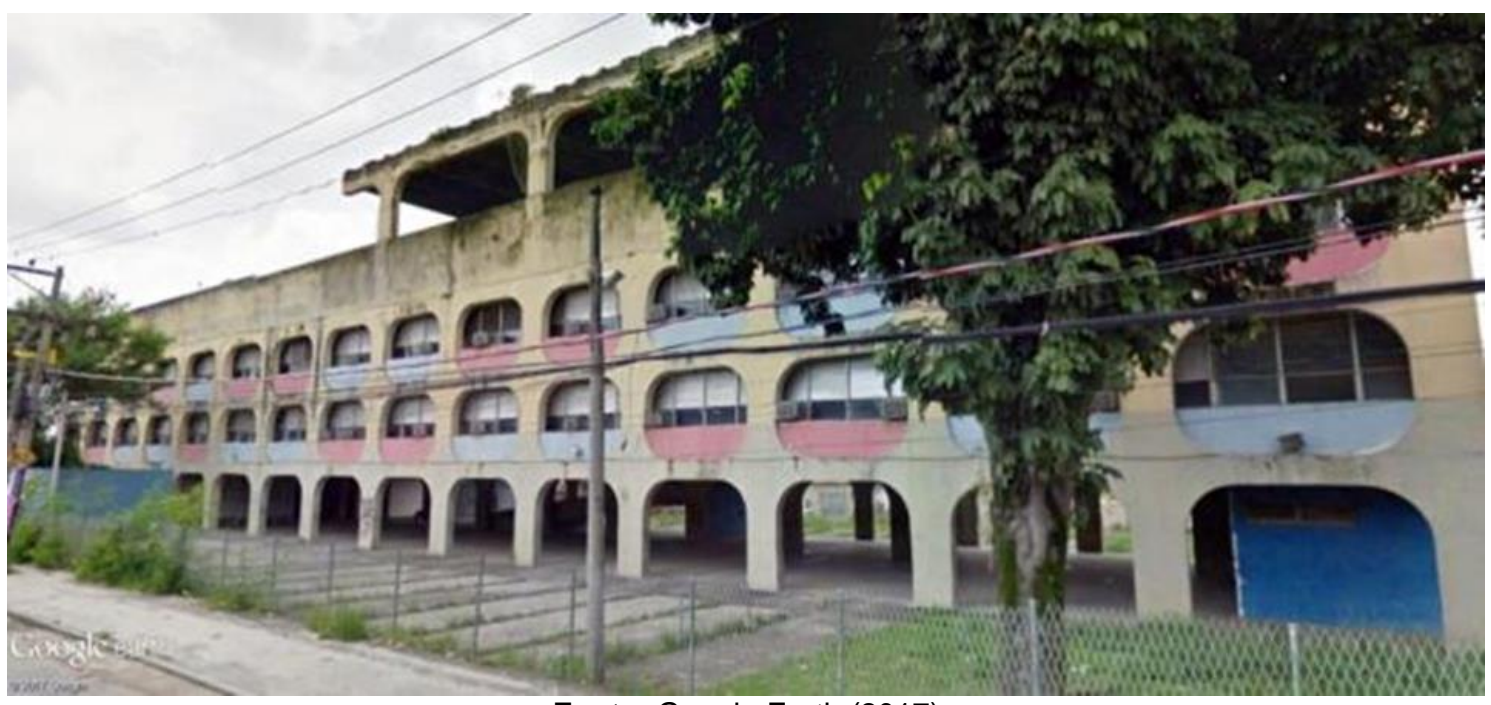

Fonte: Google Earth (2017)

O CIEP está localizado no bairro Engenho Pequeno, na divisa dos municípios de Nova Iguaçu e Belford Roxo, ambos municípios da Baixada Fluminense, no Estado do Rio de Janeiro. (Figura 02) Faz parte da bacia hidrográfica do rio Botas, mais especificamente de um de seus tributários, o Canal Maxambomba. A figura 03 mostra de forma ampliada a área de estudo com o Canal Maxambomba, retilinizado e com construções nas suas margens. 
Figura 02: Bacia do Rio Botas

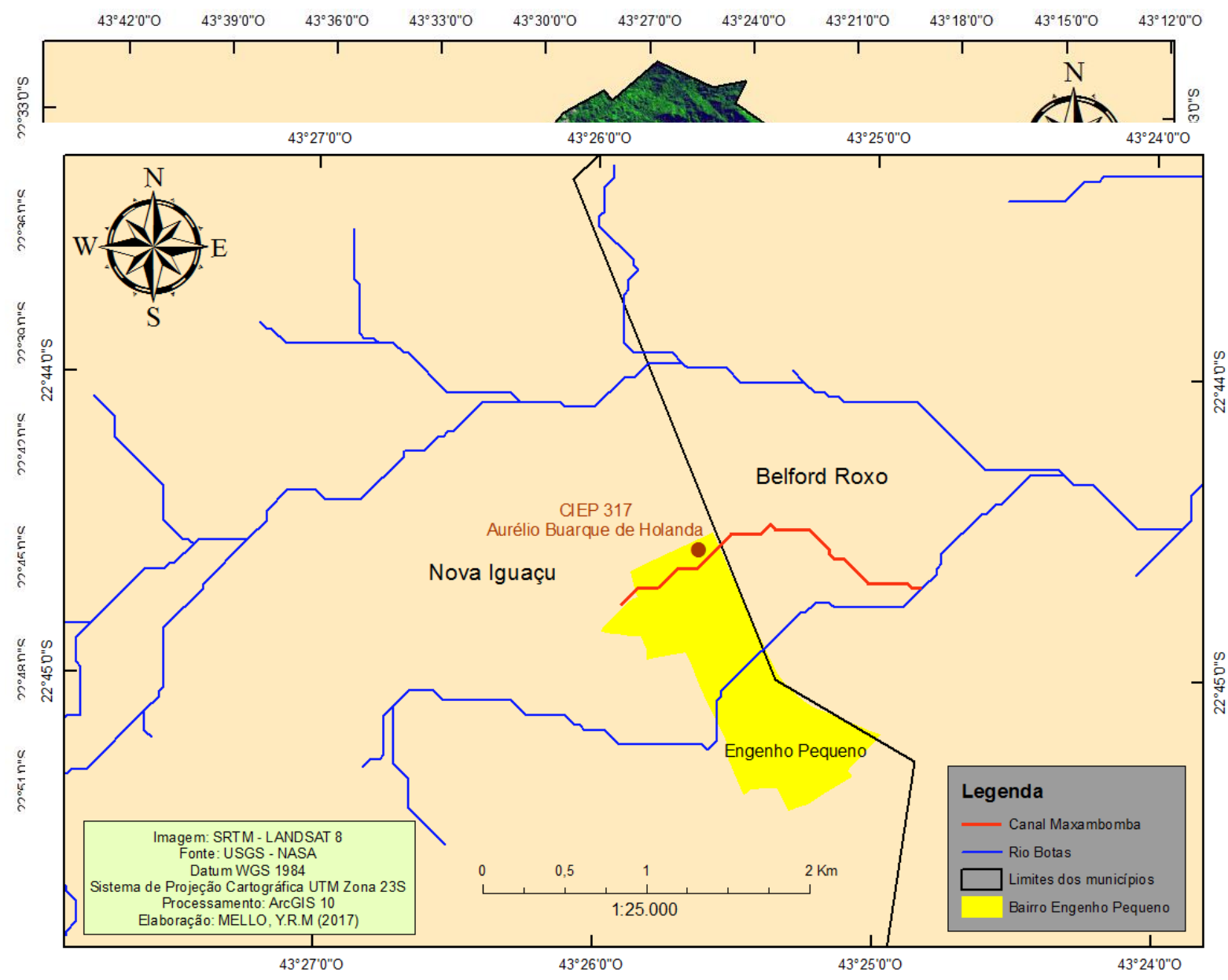

Figura 03: Canal Maxambomba

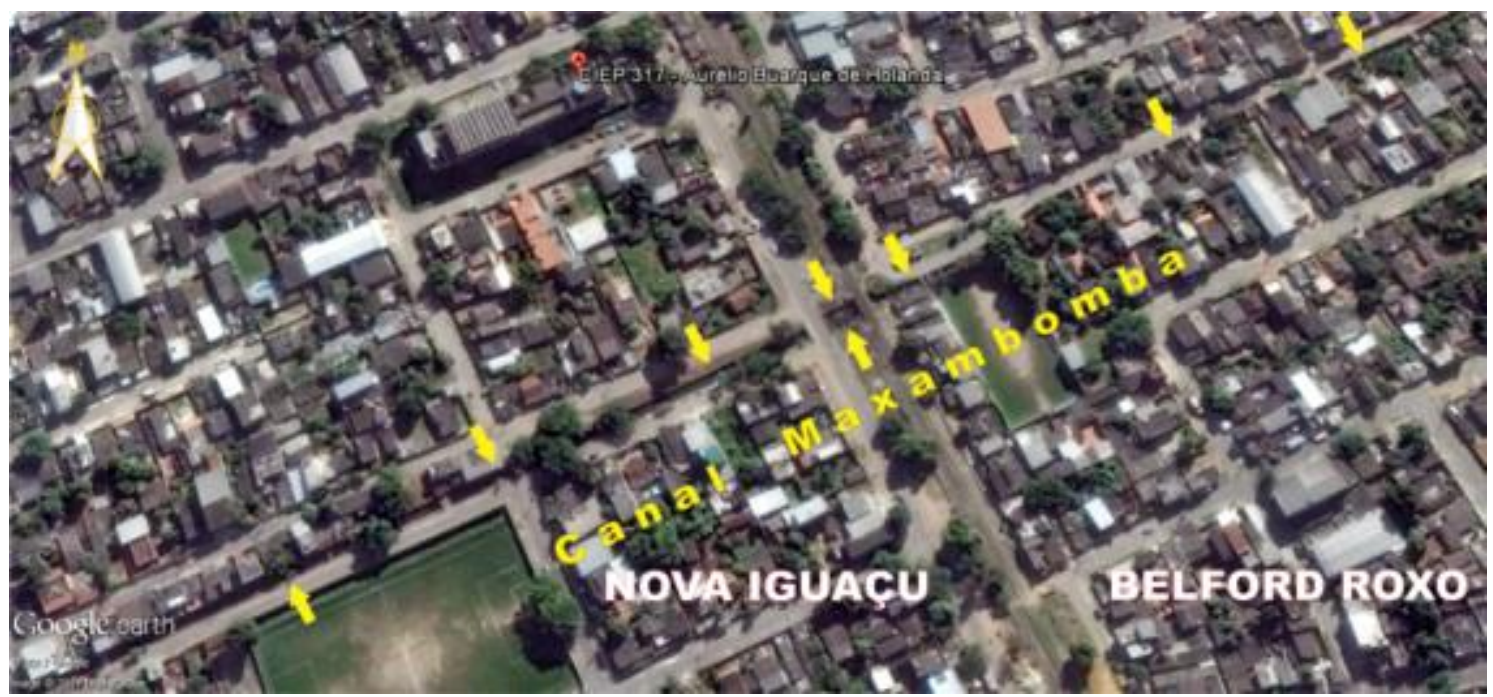

Fonte: Google Earth (2017)

$22^{\circ} 44^{\prime} 36.07^{\prime \prime} \mathrm{S} / 43^{\circ} 25^{\prime} 33.46^{\prime \prime} \mathrm{O}$ 


\section{Objetivos}

O presente trabalho possui como objetivo geral a compreensão das problemáticas hidrológicas do Canal Maxambomba. Para se alcançar tal objetivo temos os seguintes objetivos específicos, a contextualização das ações antrópicas que intervém na dinâmica natural fluvial, a tomada de consciência ambiental por parte da população local por meio da escola e o estudo crítico e reflexivo de tais problemas a partir do conceito de Lugar.

\section{Justificativa}

O Recôncavo da Guanabara pode ser compreendido como uma grande área geomorfológica, uma região de planície que se desenvolveu entre o sopé da Serra do Mar e o Oceano Atlântico, interrompida por colinas e maciços costeiros. (TAVARES, 2010), localizada no Estado do Rio de Janeiro. De acordo com Júnior (2013), essa formação geomorfológica tem sua explicação no contexto de afastamento dos continentes Sul-Americano e Africano, produzindo um sítio bastante diversificado, onde podemos perceber a ocorrência de áreas de grandes baixadas. Como é o caso do Graben da Guanabara (Figura 04), localmente dominada pela transição das escarpas da Serra dos Órgãos, para as Planícies de Alúvio-Colúvio (deposição de sedimentos dos rios da região, juntamente com os depósitos de sedimentos provenientes das encostas das montanhas) e das depressões fluviolacustres (interação entre os rios da região com os ambientes lagunares, no caso a Baía de Guanabara e a Baía de Sepetiba).

Figura 04: Perfil de relevo - Graben da Guanabara

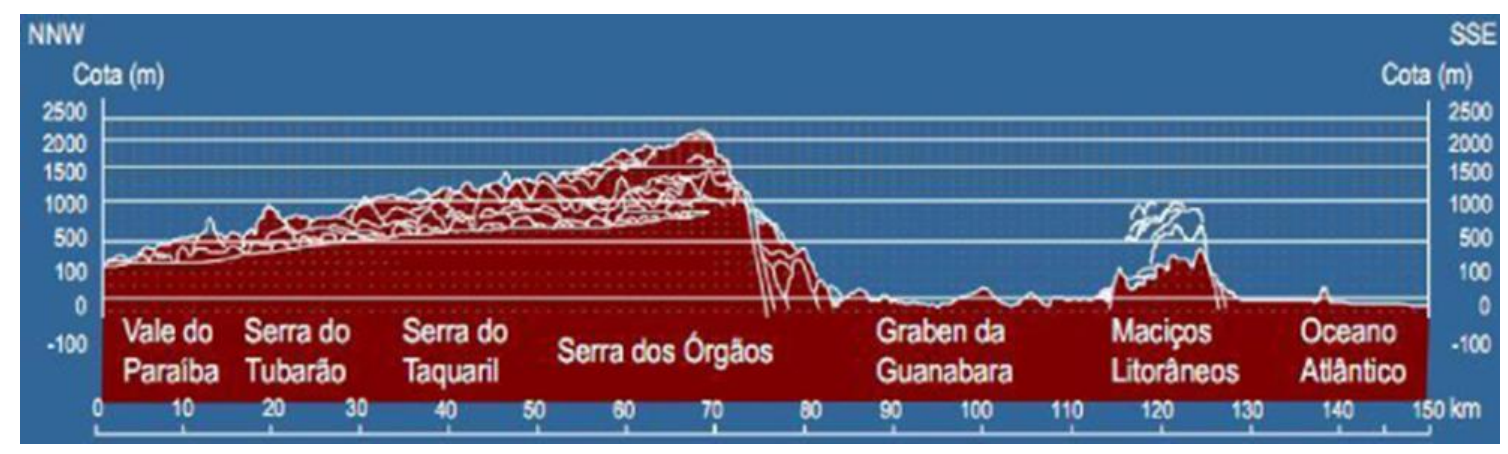

Fonte: Ruellan (1984) apud Oscar Júnior (2013)

Neste sentido, as chamadas Baixadas, são subdivisões deste recôncavo, como por exemplo, a Baixada Fluminense, que se situa entre a Serra do Mar e os maciços litorâneos. Segundo Guerra, as Baixadas se caracterizam por uma,

Área deprimida em relação aos terrenos contíguos. Geralmente se designa assim às zonas próximas ao mar, algumas vezes usa-se o termo como sinônimo de zona de planície. Geralmente esses terrenos de pequena altura na borda do mar, de baías ou de rios, são muito extensos, como é o caso da Baixada Fluminense, Baixada da Guanabara etc. (GUERRA, 2008, p.79)

Complementando a esta denominação, temos a palavra Fluminense, que está intimamente ligada à outra característica típica da região, a forte presença de rios. De acordo com (ROCHA, 2014), a hidrografia da Baixada Fluminense contribuiu tanto para compor o sítio quanto para nomear a área (Fluminense - tem origem no termo flumen- do Latim - que significa rio), onde os mesmos tiveram suma importância na ocupação territorial desta área. Neste sentido, pois, de acordo com a ideia de Simões, 
Esta geomorfologia, aliada as atuais condições climáticas, vai dar origem a uma rede hidrográfica que será de vital importância para a ocupação da Baixada Fluminense, haja vista que quase todos os núcleos iniciais que deram origem as atuais sedes de municípios surgiram como portos fluviais. (SIMÔES, 2006, p.55)

Com efeito, podemos perceber que a Baixada Fluminense é uma área naturalmente alagável, pois se trata de uma depressão relativa (mesmo nível do mar), com muitos rios meandros. Porém, a mesma sofreu uma forte intervenção antrópica, que modificou a maior parte de sua dinâmica hidrológica natural. Através das intervenções realizadas pela Diretoria de Saneamento da Baixada Fluminense DNOS houve a modificação da geomorfologia dos rios, com retilinizações e aterros das áreas alagadas. Potencializando assim as problemáticas hidrológicas desta região.

Tais problemas são recorrentes até os dias atuais, uma vez que as ações governamentais citadas acima incentivaram a ocupação irregular nas áreas de aterros e margens dos rios, com o processo de urbanização houve o asfaltamento de ruas potencializando a impermeabilidade do solo, a retirada da mata ciliar provocou o assoreamento dos rios. Aliado a estas questões ainda é latente a falta de uma conscientização ambiental de grande parte da população local, principalmente com o descarte irregular do lixo (entupindo galerias, poluindo rios e contribuindo para o seu assoreamento).

Percebe-se que a presença do homem como ser concretamente natural e, ao mesmo tempo, como alguém oposto a natureza, promoveu e ainda promove profundas transformações na natureza e na sua própria natureza. Podemos falar que vivemos em uma natureza artificial, impregnada de técnicas ou, ainda, natureza instrumental, pois as técnicas atuais, devido ao seu desenvolvimento ao longo dos tempos, permitem a sociedade realizar grandes intervenções, não só nas formas da natureza, como também nos processos naturais. (SUERTEGARAY, 2003)

Neste sentido, é de suma importância a disseminação de tais fenômenos com as diversas camadas da sociedade. A escola, com o estudo da Geografia, se torna um excelente local para a propagação de uma consciência socioambiental. $O$ estudo através do conceito de lugar contribui significativamente na formação do estudante, pois permite a valorização dos diversos modos de pensar, agir e conceber o mundo e a realização da troca destes saberes. Reconhecer os problemas socioeconômicos e socioambientais existentes no seu lugar, percebendo que não existem problemas e soluções isoladas e sim que todos estão interligados. Identificar que as matérias escolares com seus diversos conteúdos agem em conjunto, sempre na busca da compreensão e resolução destes problemas. Partindo desta premissa, a Geografia, através do lugar, permite o estudo e análise dos problemas hidrológicos da sociedade atual.

Assim, o aprendizado a partir do lugar no ensino de Geografia possibilita ao estudante fazer relações do seu cotidiano com as questões locais, regionais e globais. Na medida em que o professor se torna capaz de fazer essa relação entre as escalas, o lugar passa a ser um referencial de onde o estudante pode extrair elementos para estudar e compreender 0 mundo. $O$ estudante que consegue compreender o lugar que vive, bem como suas relações, será capaz de compreender espaços mais distantes. Isso contribui para a formação de cidadãos críticos, capazes de fazer uma leitura plena do mundo em que vivem.

\section{METODOLOGIA}

Foi realizada uma pesquisa bibliográfica para contextualizar historicamente os problemas hidrológicos urbanos do município de Nova Iguaçu. Tal pesquisa focou no processo de urbanização da região, principalmente nos incentivos governamentais. Enfatizou-se as obras de saneamento da baixada fluminense, pois as mesmas modificaram drasticamente a dinâmica fluvial da região.

Também foi realizada uma pesquisa bibliográfica para a conceituação de Lugar, focando o uso deste conceito nas práticas escolares no ensino de Geografia. Tal conceito foi utilizado para realizar a transposição didática dos conteúdos científicos e aproximar a realidade e experiências locais dos estudantes do aprendizado escolar.

Como parte prática foi realizado um projeto no CIEP Aurélio Buarque de Holanda. Tal projeto teve como ponto de partida o uso de temas geradores e o uso do conceito de Lugar. As problemáticas hidrológicas foram abordadas a partir da realidade do bairro, utilizando notícias de jornais e observação do Canal Maxambomba, identificando seus principais problemas. Como fechamento do projeto foram discutidos e propostas possíveis soluções para tais problemáticas.

$\begin{array}{llllll}\text { Caminhos de Geografia } & \text { Uberlândia - MG } & \text { v. 19, n. } 68 & \text { Dez/2018 } & \text { p. 116-131 } & \text { Página } 121\end{array}$




\section{RESULTADOS E DISCUSSÃO}

A região da Baixada Fluminense, no Estado do Rio de Janeiro, convive constantemente com problemas de ordem hidrológica, como enchentes, alagamentos e enxurradas. Tais problemas não são atuais, existem desde épocas pretéritas, remontam do período colonial com suas primeiras ocupações. Suas origens são essencialmente naturais, pois a presente região possui naturalmente muitos rios meandrantes, com extensas áreas de alagadiços. Entretanto, para tentar solucionar estes problemas, que assolam a região desde séculos passados, a partir do início do século XX diversas frentes de trabalhos foram criadas para a implementação de grandes obras de saneamento, com o objetivo final de fomentar o crescimento econômico da baixada, contribuindo inclusive, para o seu rápido crescimento urbano.

Possuíam como discurso hegemônico a higienização e combate às frequentes enchentes e inundações que assolavam a região, desta forma, colocando estes espaços em lugares "adequados", dignos para se viver e investir, livres de epidemias e enchentes, além de limpos. Assim, os objetivos destas obras se constituíam em tornar as áreas ditas como insalubres, ou seja, as áreas naturais de inundações dos rios da região, em terras produtivas, que poderiam servir para, primeiramente, a implementação de terras agrícolas e posteriormente para a criação de indústrias, bem como para moradias de trabalhadores. Para fazer estes trabalhos de saneamento, houve a seleção das áreas, mensurando o valor das terras, a densidade dos núcleos de população e a proximidade dos grandes centros de consumo (TAVARES, 2010)

Tais obras foram financiadas pelo governo, sendo as realizadas pela então Diretoria de Saneamento da Baixada Fluminense, criada em 1930 e dirigida pelo engenheiro Hildebrando de Góes, a mais atuante no recorte espacial do presente artigo. No relatório sobre as obras de saneamento do engenheiro Hildebrando de Góes, podemos destacar aquelas ações que influenciaram de forma marcante a dinâmica da geomorfologia fluvial urbana que existe atualmente no município de Nova Iguaçu.

Entre estas medidas podemos citar a recuperação de áreas alagadas (rios assoreados), nas quais houve um intenso processo de limpeza dos rios, retirando dos mesmos troncos e galhos de árvores, os sedimentos depositados no fundo do leito principal e toda a cobertura vegetal de plantas aquáticas, como o aguapé. Através destas ações foi realizada a primeira marcação mais precisa sobre a vazão dos rios, bem como a delimitação da área de abrangência do extravasamento das águas nos leitos menores e maiores dos mesmos.

A dragagem de leitos de rios para a regularização do fluxo, bem como o aprofundamento do leito principal, com o objetivo de aumentar a sua capacidade de escoamento e torná-lo novamente navegável. A retilinização e canalização dos rios meandros da região para a drenagem de áreas ditas pantanosas, consideradas, portanto como local de foco de doenças, ou seja, aquelas que estavam permanentemente alagadas nas margens dos rios. A construção de diques artificiais auxiliares, localizados no leito menor, onde as águas oriundas das enchentes iriam penetrar, sendo transportadas e escoadas para o mar ou para outros cursos de água, acreditava-se que desta forma as águas não iriam invadir as áreas povoadas.

Conforme explicitado por Amador (1997), as intervenções das obras de saneamento na Baixada Fluminense foi um dos episódios mais perversos de agressão à natureza que ocorreu neste local. Foram utilizados grandes volumes de recursos públicos na valorização de terras de grandes proprietários, que as venderam com alta taxa de lucratividade aos proletários que vieram a ser estabelecer na baixada para trabalhar nas indústrias da região. Desta forma, gerando um grande acúmulo de capital nas mãos de poucos. Ainda segundo Amador,

Os loteamentos que passaram a proliferar com o "saneamento" da Baixada, não demorariam a conviver com as inundações crônicas, que não cessariam mesmo com a continuação das obras pelo DNOS. Além das cheias, no entanto, a população sofrida e proletária da Baixada, conviveria ainda com a ausência quase que absoluta de serviços públicos de água, esgoto, coleta de lixo, transporte e um meio ambiente impróprio para abrigar um adensamento populacional. (AMADOR, 1997, p.338)

Mesmo diante de todas estas intervenções pelo poder público, com o objetivo de conter problemas de ordem hidrológica tipicamente urbana (enchentes, inundações, alagamentos e enxurradas), no

\begin{tabular}{llllll}
\hline Caminhos de Geografia & Uberlândia - MG & v. 19, n. 68 & Dez/2018 & p. 116-131 Página 122
\end{tabular}


município de Nova Iguaçu, na Baixada Fluminense, tais problemas continuam de forma frequente. Neste sentido, podemos perceber que a continuidade destes problemas está diretamente relacionada com alguns fatores condicionantes, sejam eles naturais ou antrópicos. O Instituto Geológico do Estado de São Paulo, em seu caderno sobre Desastres Naturais, divide estes condicionantes em fatores naturais e os fatores antrópicos que interferem na dinâmica natural.

Dentre os fatores condicionantes naturais podemos destacar a geomorfologia do lugar; as características da rede de drenagem da bacia hidrográfica; a intensidade, quantidade, distribuição e frequência das chuvas; as características do solo e a presença ou ausência da cobertura vegetal. No que tange aos fatores condicionantes antrópicos podemos destacar, o uso e ocupação irregular nas planícies e margens de cursos d'água; a disposição irregular de lixo nas proximidades dos cursos d'água; as alterações nas características da bacia hidrográfica e dos cursos d'água; a retificação e canalização de cursos d'água, a impermeabilização do solo e o intenso processo de erosão dos solos e de assoreamento dos cursos d'água. (TOMINAGA et al, 2009)

Esta complexa problemática hidrológica que ocorre em áreas densamente ocupadas, como o meio urbano, acaba por gerar muitos prejuízos de cunho financeiros, sociais e ambientais. Exemplificado na tabela 01. Ocorrendo por muitas vezes a perda de bens materiais, incluindo a própria moradia, assim como perdas não materiais, como o falecimento de pessoas. Além desses fatores ainda existe a alta possibilidade de contrair doenças transmitidas por bactérias na água, como a leptospirose, a febre tifóide, a hepatite e a cólera, que se proliferam através de transmissores como mosquitos e ratos, além da poluição por dejetos orgânicos e/ou industriais.

Tabela 01: Comparativo entre a problemática hidrológica urbana e seus impactos socioambientais

\begin{tabular}{|l|l|}
\hline \multicolumn{1}{|c|}{ Problema Hídrológico } & \multicolumn{1}{c|}{ Impacto Socioambiental } \\
\hline Inundações & $\begin{array}{l}\text { Perdas de bens materiais, como construções e } \\
\text { móveis; } \\
\text { Perdas de bens não materiais, como vidas } \\
\text { humanas e de animais; } \\
\text { Enchentes } \\
\text { Contágio de doenças por animais transmissores } \\
\text { ou por bactérias devido à poluição dos rios. }\end{array}$ \\
\hline Enxurradas & $\begin{array}{l}\text { Maior probabilidade de ser constantemente } \\
\text { atingido por enchentes, inundações e contágio de } \\
\text { doenças; } \\
\text { Maiores perdas materiais (construções/móveis) e } \\
\text { imateriais (vidas humanas e de animais). }\end{array}$ \\
\hline Intervenção Humana & $\begin{array}{l}\text { Intensificação da ocorrência de enchentes e } \\
\text { inundações, devido à diminuição da vazão do rio, } \\
\text { diminuição da profundidade da calha do rio. }\end{array}$ \\
\hline Assoreamento & $\begin{array}{l}\text { Aumento dos pontos de alagamentos, enxurradas } \\
\text { e inundações. }\end{array}$ \\
\hline Impermeabilidade do Solo & $\begin{array}{l}\text { Proliferação de animais transmissores de } \\
\text { doenças; } \\
\text { Poluição dos cursos d'água e dos lençóis } \\
\text { freáticos; } \\
\text { Diminuição da drenagem urbana e aumento dos } \\
\text { pontos de alagamentos. }\end{array}$ \\
\hline Lixo & Fonte: Elaborado pelo autor (2016) \\
\hline
\end{tabular}

Neste sentido podemos compreender que a degradação ambiental que ocorre nos meios urbanos, não deixa de ser um problema social, que também contribui com grande parcela para a ocorrência dos problemas hídricos urbanos, ou seja, os mesmos se caracterizam como problemas 
socioambientais. Podemos perceber, através das notícias de jornais locais e nacionais, que estes problemas hidrológicos são constantes, principalmente no contexto da bacia do Rio Botas.

Outro aspecto que podemos destacar, é que na maioria das notícias veiculadas, não se focaliza o contexto social destes problemas hídricos, ficando estes em segundo plano, e sim aspectos relativos a obras de engenharia, vinculadas a noção de que através da execução das mesmas os problemas estarão solucionados. Apenas em uma notícia, o aspecto social aparece de forma clara e direta. Abaixo descrevemos algumas reportagens que destacaram a problemática hidrológica na Bacia do Rio Botas no município de Nova Iguaçu (Tabela 02).

Tabela 02: Comparativo do contexto socioambiental das notícias de jornais

\begin{tabular}{|c|c|c|c|}
\hline JORNAL & CONTEXTO SOCIAL & CONTEXTO AMBIENTAL & $\begin{array}{c}\text { INTERVENSÃO } \\
\text { HUMANA }\end{array}$ \\
\hline Portal G1 & $\begin{array}{l}\text { Pessoas desalojadas; } \\
\text { Recebimento de ajuda } \\
\text { através de doações; } \\
\text { Casas atingidas pelas águas }\end{array}$ & $\begin{array}{l}\text { Transbordamento do Rio } \\
\text { Botas e de seu afluente, o } \\
\text { Canal Maxambomba }\end{array}$ & Não aborda \\
\hline SB Notícias & $\begin{array}{l}\text { Prevenção contra novas } \\
\text { enchentes no verão }\end{array}$ & Assoreamento do Rio Botas & $\begin{array}{l}\text { Desassoreamento do Rio } \\
\text { Botas com a retirada de lixo e } \\
\text { entulho do canal }\end{array}$ \\
\hline $\begin{array}{l}\text { Folha do } \\
\text { lguassú }\end{array}$ & $\begin{array}{l}\text { Prevenção contra novas } \\
\text { enchentes e proliferação de } \\
\text { doenças no verão; } \\
\text { Pessoas desabrigadas e } \\
\text { desalojadas }\end{array}$ & $\begin{array}{l}\text { Afluentes do Rio Botas } \\
\text { obstruídos; } \\
\text { Chuvas intensas; } \\
\text { Afluentes poluídos com focos } \\
\text { de proliferação de mosquitos e } \\
\text { ratos }\end{array}$ & $\begin{array}{l}\text { Dragagem dos afluentes do } \\
\text { Rio Botas; } \\
\text { Construção de pontes e } \\
\text { limpeza do Canal } \\
\text { Maxambomba }\end{array}$ \\
\hline$E B C$ & $\begin{array}{l}\text { Ocupação desordenada nas } \\
\text { áreas de APP }\end{array}$ & $\begin{array}{l}\text { Rio Botas assoreado; } \\
\text { Não cumprimento do código } \\
\text { florestal }\end{array}$ & $\begin{array}{l}\text { Levantamento com relatório } \\
\text { detalhado para buscar } \\
\text { soluções sustentáveis }\end{array}$ \\
\hline \multicolumn{4}{|c|}{ Fonte: Elaborado pelo autor (2016) } \\
\hline
\end{tabular}

Portal G1 - Nova Iguaçu realiza força-tarefa para combater as enchentes. Equipes da Defesa Civil e do Corpo de Bombeiros foram acionadas para auxiliar as pessoas atingidas pelos alagamentos, devido ao transbordamento do Rio Botas e do Canal Maxambomba, onde cerca de 10 bairros e 200 famílias foram afetadas. Já se iniciou o processo de ajuda as famílias atingidas, com a arrecadação de mantimentos, através de doações, além da distribuição de cestas básicas. As famílias foram alojadas provisoriamente em escolas da região. (30 de novembro de 2006)

SB Notícias - De acordo com ABREU, Marcelle, a população de Nova Iguaçu começa a se prevenir contra as enchentes de verão. O objetivo é realizar o desassoreamento do Rio Botas, retirando a cada dia cerca de 200 toneladas de lixo, entulhos e terra. (13 de dezembro de 2010)

Folha do Iguassú - Segundo CAMARA, Wandemberg, a Prefeitura de Nova Iguaçu começou a realizar a dragagem de afluentes do Rio Botas com o objetivo de prevenir novas enchentes. (29 de novembro de 2013)

Folha do Iguassú - De acordo com CAMARA, Wandemberg, o município de Nova Iguaçu tem 1.100 desabrigados e desalojados em 26 regiões da cidade devido a fortes chuvas que atingiram a região. (12 de dezembro de 2013)

$E B C$ - Segundo AMADO, Aécio, o CREA realizou visitas a pontos críticos de enchentes em Nova Iguaçu. Um dos pontos visitados foram os trechos mais críticos do Rio Botas,

$\begin{array}{llllll}\text { Caminhos de Geografia } & \text { Uberlândia - MG } & \text { v. 19, n. 68 } & \text { Dez/2018 } & \text { p. 116-131 Página } 124\end{array}$


onde foram detectados problemas como assoreamento, pontes impedindo a passagem da água, ocupações desordenadas e desrespeito com o código florestal. As visitas possuem como objetivo realizar um levantamento detalhado de problemas e promover soluções sustentáveis. (19 de dezembro de 2013)

Folha do Iguassú - Como explicita CAMARA, Wandemberg, o Prefeito de Nova Iguaçu realizou a inspeção de obras de drenagem, a construção de pontes e a limpeza do Canal Maxambomba para a prevenção de enchentes. Acredita-se que estas intervenções irão por fim nas constantes enchentes e na proliferação de ratos e mosquitos na região. (20 de outubro de 2015).

Toda esta dinâmica socioambiental foi utilizada para promover o projeto realizado no CIEP Aurélio Buarque de Holanda. Para promover o debate sobre as problemáticas hidrológicas urbanas na escola, foi necessário realizar uma contextualização histórica da região. Posteriormente foram expostas as notícias de jornais, onde as mesmas foram contextualizadas com a realidade local, inclusive com as experiências vivenciadas com os próprios estudantes.

Através das atividades realizadas na escola, os estudantes estabeleceram os principais problemas socioambientais encontrados no bairro, quais são as suas causas, bem como possíveis soluções para minimizar tais problemas. Todas as questões apresentadas pelos mesmos tiveram como ponto de partida as consequências históricas das intervenções humanas na dinâmica natural da Baixada Fluminense.

Com efeito, foi possível compreender que as intervenções da Diretoria de Saneamento da Baixada Fluminense, ocorridas na primeira metade do Séc.XX, ainda são muito latentes nos dias atuais, sendo percebido pelos moradores do bairro Engenho Pequeno. Na tentativa de elucidar o fato gerador destas obras, se faz necessário retomar quais foram os principais argumentos utilizados pelos engenheiros e governantes daquela época para realizar tais intervenções.

Os principais objetivos figuravam sob a alegação de transformar a Baixada Fluminense em um lugar considerado salubre, ou seja, sem a proliferação de animais transmissores de doenças, bem como sem a ocorrência de alagadiços e enchentes. Neste sentido, podemos perceber que tais intervenções não lograram êxito, pois um dos grandes problemas apontados pelos estudantes diz respeito justamente à proliferação de doenças através do contato com animais, pela água contaminada por esgoto doméstico (Figuras: 05) e industrial, bem como o acúmulo de lixo urbano (Figura: 06) nas margens dos rios. Os mesmos sinalizaram a existência de todo um corredor de casas, que não possuem saneamento básico, depositando o esgoto doméstico ao longo do curso do canal Maxambomba. (Figura: 07)

Figura 05: Esgoto doméstico no Canal Maxambomba

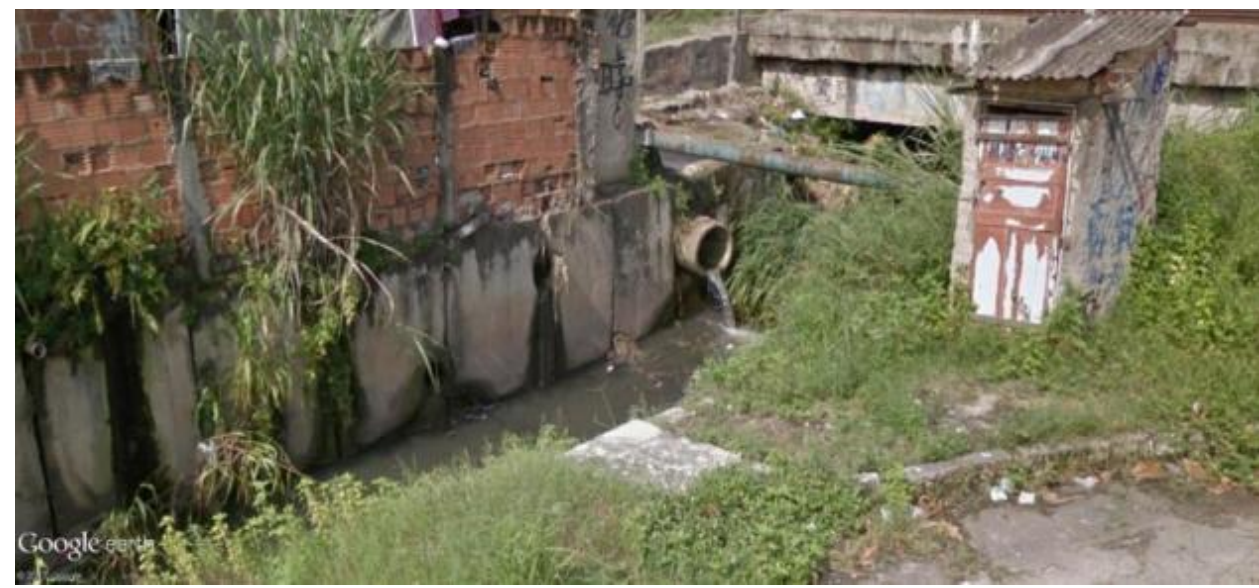

Fonte: Google Earth (2017) 
Figura 06: Lixo depositado no Canal Maxambomba

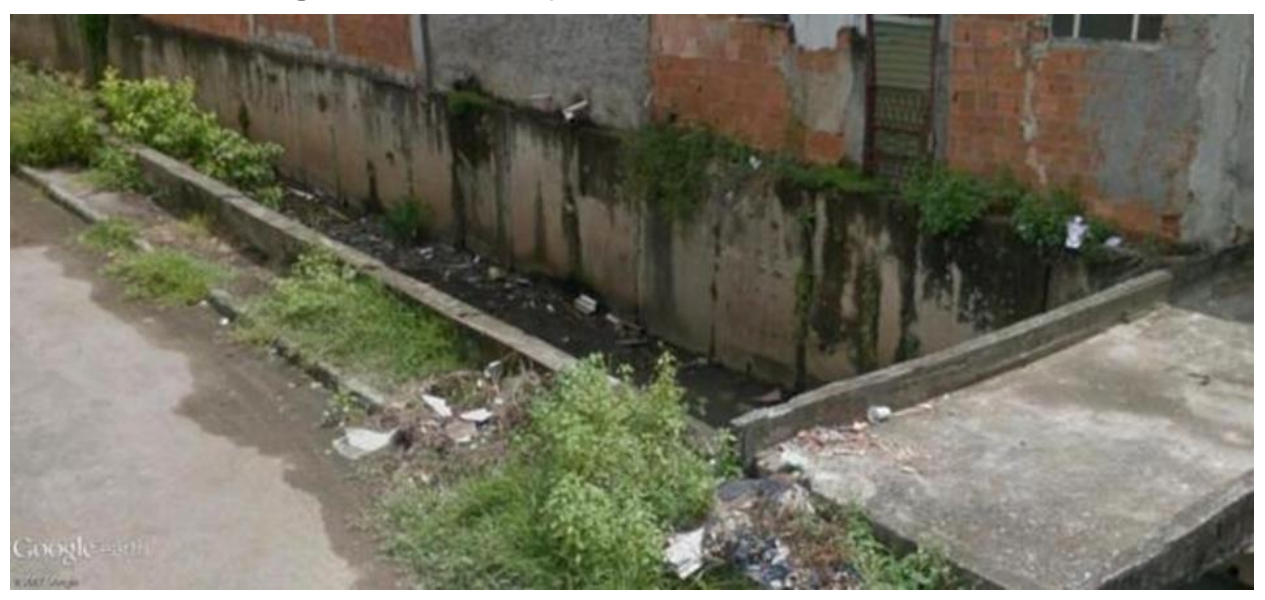

Fonte: Google Earth (2017)

Figura 07: Casas na margem do Canal Maxambomba
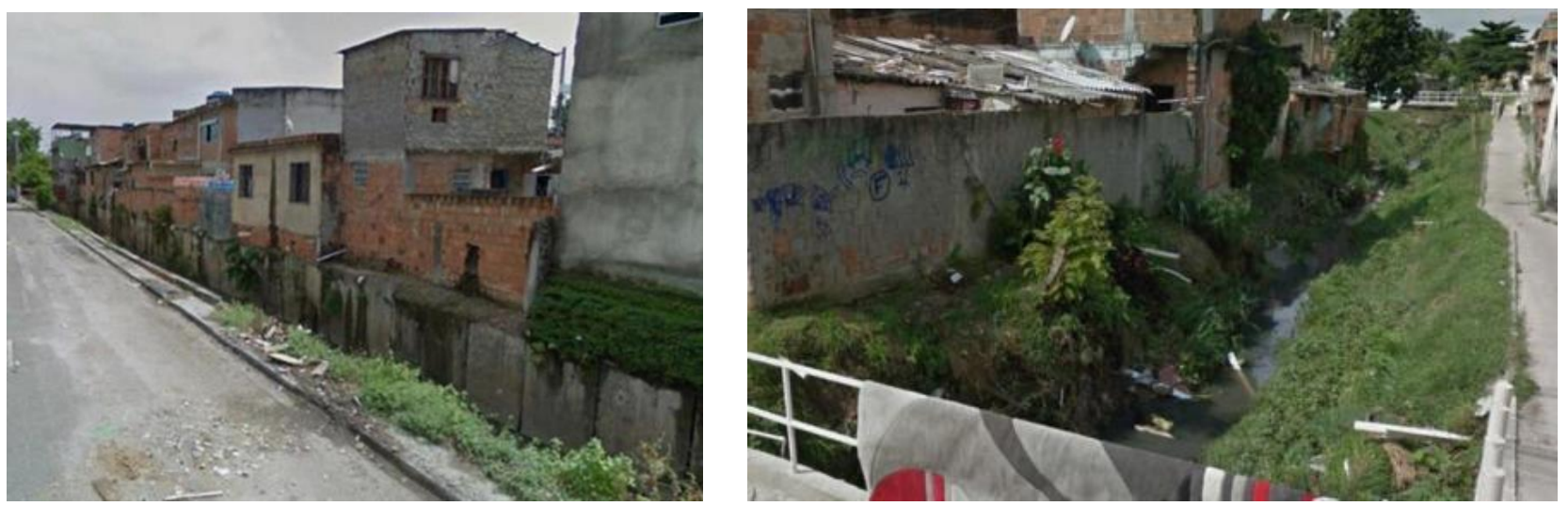

Fonte: Google Earth (2017)

As moradias em sua maioria são precárias, que segundo as histórias que os estudantes ouviram de seus familiares, tais terrenos e casas foram adquiridos pela população migrante de menor poder aquisitivo. Um estudante reside com sua família em uma moradia localizada na beira do canal Maxambomba. Sua família migrou de onde morava para este local, adquirindo o terreno com o intuito de crescer economicamente, pois acreditavam que pelo fato de estarem próximos da Cidade do Rio de Janeiro, surgiria melhores oportunidades de trabalho. Entretanto, em decorrência do baixo grau de escolaridade o crescimento econômico esperado não ocorreu, permanecendo em condições precárias de vida.

Este exemplo citado acima ocorreu com boa parte da população do bairro Engenho Pequeno, que ainda hoje sofre com os prejuízos causados pelas enchentes na região. Vale destacar que, tais moradias estão localizadas em área de proteção permanente do rio - APP (Figura: 08), ou seja, justamente no perímetro, que se estivesse preservado, auxiliaria na prevenção de enchentes e na manutenção daquele corpo d'água. 
Figura 08: Casas construídas no leito do canal Maxambomba

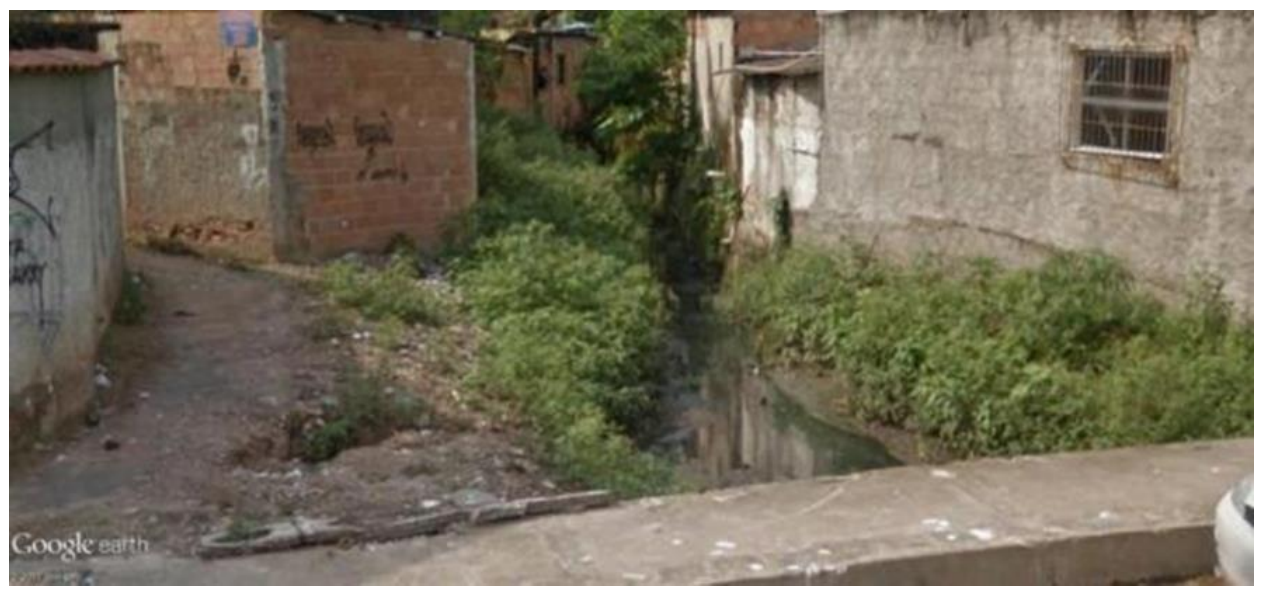

Fonte: Google Earth (2017)

No passado as ações antrópicas que ocasionaram as modificações da dinâmica hidrológica do canal Maxambomba, como a sua retilinização e concretização, além do desmatamento da mata ciliar, potencializaram o assoreamento deste corpo d'água. No presente são necessárias intervenções diretas e constantes da prefeitura ao longo do ano neste canal, principalmente nos meses de verão, com o objetivo de retirar todo o entulho que se acumula e se mistura com a carga de sedimentos oriundos do assoreamento, para evitar o transbordamento do Maxambomba nos períodos de maiores índices pluviométricos.

Atualmente o canal Maxambomba se encontra em tamanha desconfiguração de seu aspecto e funcionalidades naturais, que os moradores locais e a própria prefeitura, o denominam de "valão". (Figura: 09) O mesmo funciona como uma grande vala a céu aberto para despejar o esgoto doméstico, além do lixo não recolhido pela prefeitura, transformando-o em um dos principais locais de proliferação de animais transmissores de doenças.

Figura 09: Canal Maxambomba em grande estado de degradação

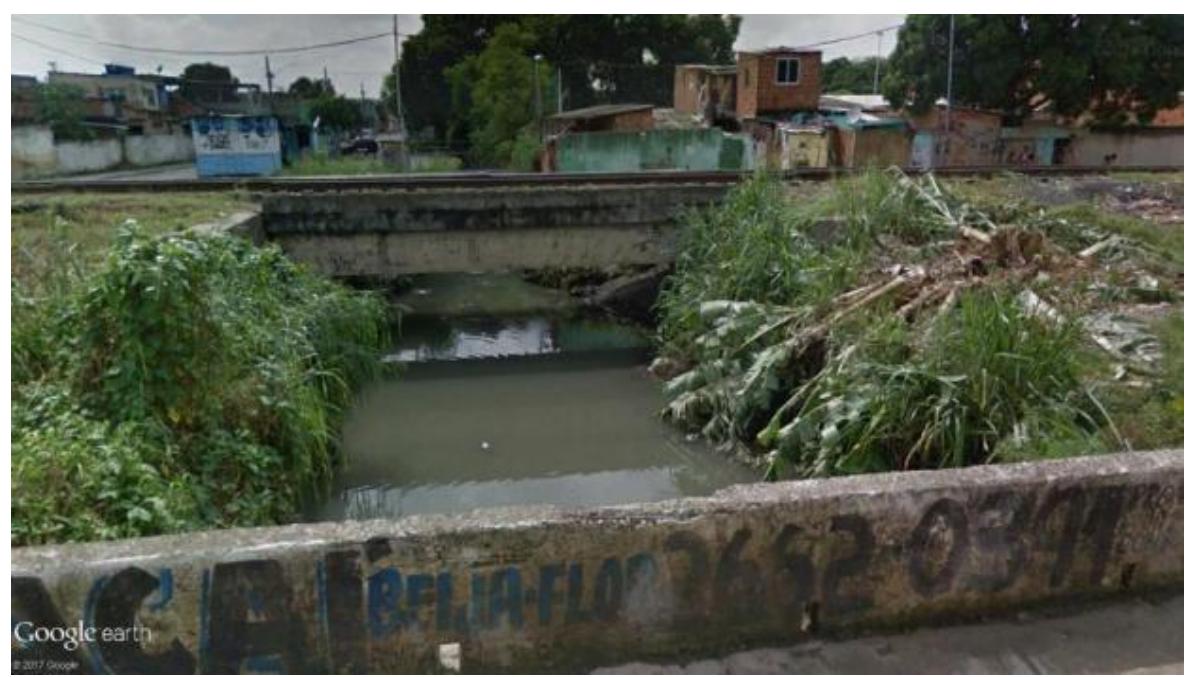

Fonte: Google Earth (2017) 
Com as atividades realizadas na escola os estudantes demonstraram que o aprendizado desta temática é necessário para criar uma consciência crítica a respeito dos impactos socioambientais, delineando soluções para minimizar ou até resolver tais problemas. Estas soluções começariam pelas ações na própria comunidade. Este aprendizado também fortaleceu a capacidade de argumentação dos estudantes e a tomada de decisões. As maiores contribuições que os mesmos deram ao projeto dizem respeito às soluções para minimizar ou até acabarem com os principais problemas socioambientais que ocorrem no bairro Engenho Pequeno.

Entre as soluções apresentadas existem basicamente quatro tipos: No primeiro tipo estão aquelas de carácter individual, na qual cada cidadão faz a sua parte, assim se todos fizerem ao mesmo tempo, teremos um grande resultado, pois todas as ações individuais se unirão, formando uma ação coletiva, abrangendo muitas pessoas. Um bom exemplo desta maneira de pensar está exposto nas campanhas de não jogar lixo nas ruas e rios. De acordo com tais campanhas, se todos os cidadãos pararem de jogar lixo nos lugares errados e passarem a depositá-los nas lixeiras os rios e ruas serão automaticamente limpos, sem a necessidade de outras intervenções. No segundo tipo estão aquelas que exigem um engajamento da comunidade para cobrar da prefeitura os serviços mínimos que cabem à mesma oferecer.

O terceiro tipo diz respeito à tomada de consciência da comunidade acerca destes problemas, envolvendo a participação ativa de todos, em um diálogo aberto, onde possam conhecer as consequências que tais problemas causam nas suas vidas e juntos procurar maneiras de solucionálas. Este conhecimento vem através dos estudos na escola, onde os próprios estudantes podem repassá-los em reuniões comunitárias, nas suas casas e para amigos.

E o quarto tipo também se caracteriza pela tomada de consciência, porém, não apenas da comunidade, mas também de empresas e indústrias que empregam a população local e que muitas vezes estão instaladas nestas localidades. As mesmas também precisam ter ações que visam a não poluição e a não degradação do meio ambiente, além de dar um retorno à comunidade, através de ações que primam por uma melhor qualidade de vida, principalmente na questão meio ambiente. É necessário o diálogo e o envolvimento entre empresas, indústrias e comunidade.

Tabela 03: Síntese das possíveis soluções idealizadas pelos estudantes

\begin{tabular}{|c|c|}
\hline Ações Individuais & $\begin{array}{l}\text { - Não jogar lixo nas ruas e no rio; } \\
\text { - Não realizar queimadas nas margens do rio; } \\
\text { - Aprender sobre os problemas } \\
\text { socioambientais; } \\
\text { - Participar de reunião e ações comunitárias em } \\
\text { prol da preservação ambiental; } \\
\text { - Passar para o próximo os conteúdos } \\
\text { aprendidos na escola. }\end{array}$ \\
\hline Ações comunitárias com a prefeitura & $\begin{array}{l}\text { - Exigir o serviço de coleta de lixo no bairro, } \\
\text { principalmente nas áreas mais distantes e de } \\
\text { difícil acesso; } \\
\text { - Preservar as áreas verdes, principalmente a } \\
\text { mata ciliar; } \\
\text { - Criar áreas verdes e de lazer, como parques e } \\
\text { praças; } \\
\text { - Limpar e preservar os rios; } \\
\text { - Oferecer saneamento básico para toda a } \\
\text { população, principalmente a mais carente. }\end{array}$ \\
\hline Diálogo comunitário & $\begin{array}{l}\text { - Compreender que o meio ambiente é um bem } \\
\text { coletivo, importante para toda a sociedade e } \\
\text { neste sentido deve ser preservado por todos. }\end{array}$ \\
\hline Ações empresariais e industriais & $\begin{array}{l}\text { - Realizar programas de educação ambiental; } \\
\text { - Destinar corretamente seus resíduos; } \\
\text { - Promover ações de preservação do meio } \\
\text { ambiente. }\end{array}$ \\
\hline
\end{tabular}

$\begin{array}{llllll}\text { Caminhos de Geografia } & \text { Uberlândia - MG } & \text { v. 19, n. } 68 & \text { Dez/2018 } & \text { p. 116-131 Página } 128\end{array}$


Como é possível perceber, diante de tantas ações realizadas por diversos órgãos institucionais, estes problemas hidrológicos não cessaram, muitos inclusive se intensificaram. Com o objetivo de tentar procurar soluções mais adequadas para a atualidade, refletindo sobre a nossa interligação com estes processos hidrológicos, Botelho sinaliza que,

\begin{abstract}
Faz-se necessária a adoção de novos paradigmas, novos conceitos, novas visões e novas medidas que garantam o melhor funcionamento das bacias de drenagem urbanas, de modo a combater e prevenir problemas ambientais, notadamente as enchentes e a degradação dos corpos hídricos. (BOTELHO, 2011, p.93)
\end{abstract}

Não podemos desfazer tudo que já existe, realizando um processo de desconstrução do meio urbano, mas podemos criar mecanismos, com ações que busquem um equilíbrio, com uma relação integrada entre a sociedade com o meio natural, observando suas dinâmicas. Desta forma, elaborando Planos Diretores que levem em consideração toda a dinâmica fluvial.

Neste sentido, a educação torna-se uma ferramenta indispensável para o entendimento e aprofundamento da sociedade perante estas questões, como um exemplo da importância da disseminação de informações, podemos citar a prevenção contra a ocorrência de desastres naturais, como deslizamentos e inundações. Uma população que compreenda estes processos poderá perceber uma possível ocorrência e se preparar antes de acontecer.

Ainda com base no papel que a educação possui nestas questões, podemos dizer que a partir do ensino da Geografia, principalmente a partir do estudo do Lugar, se faz de suma importância, compreender os processos hidrológicos do seu espaço vivido facilitando e tornando significativo este entendimento, podendo posteriormente ser ampliado para outras escalas, como o regional e o nacional. É necessário que os estudantes percebam que os rios são pertencentes ao seu Lugar e que fazem parte de suas vidas, pois vivemos em um mundo onde existe toda uma complexa relação socioambiental. Desta forma, realizando uma reflexão crítica sobre estes processos hidrológicos e como a nossa sociedade interfere nos mesmos, sendo prejudicada por suas próprias ações.

Botelho (2011) dialoga com este movimento de se compreender as causas e os efeitos dos processos hidrológicos, ela defende que existe um desencontro entre eles, muito prejudicial a nossa sociedade e a natureza. Infelizmente são poucas as pessoas que possuem a noção que habitam em regiões de bacias hidrográficas, sendo componentes e elementos das mesmas. Assim, podemos afirmar que nosso endereço precisa ser mais do que uma rua, um bairro e uma cidade; precisa ser também uma bacia hidrográfica. Vale ressaltar aqui que só se pode cuidar daquilo que se conhece. Não se pode proteger o desconhecido.

A nossa sociedade precisa conviver com estes processos, mas quando um evento natural acaba por trazer prejuízos financeiros e sociais, o homem sente a necessidade de intervir no meio natural, a lógica que a sociedade é superior à natureza. Como bem mostrado acima, estas intervenções não trouxeram benefícios reais para a nossa sociedade, pelo contrário, muitas até agravaram os processos hidrológicos naturais. Portanto, a reflexão crítica sobre estes processos hidrológicos busca mostrar que a nossa sociedade faz parte das dinâmicas das bacias hidrográficas, sendo, desta forma, de suma importância o desenvolvimento do sentimento de pertencimento através do estudo do Lugar.

\title{
CONSIDERAÇÕES FINAIS
}

O presente artigo contemplou a discussão e a análise das modificações que a sociedade imprimiu sobre o meio natural do município de Nova Iguaçu, mais especificamente no bairro Engenho Pequeno. Pode-se inferir que tais problemas possuem suas origens na dinâmica natural fluvial da região, porém, com as intervenções antrópicas realizadas, os mesmos foram potencializados.

Tais modificações que ocorreram no espaço-tempo presentes no recorte espacial supracitado figuraram como fonte do tema gerador, o qual é muito latente na vida dos estudantes, pois o convívio cotidiano com as problemáticas hidrológicas é uma constante na dinâmica social destas pessoas. As atividades realizadas primaram pela busca de informações por parte dos estudantes, objetivando a geração de saberes escolares acerca do tema estudado, bem como a ampliação desses saberes escolares com a vivência no bairro. 
Com efeito, foi possível compreender as problemáticas hidrológicas presentes no recorte espacial, no Canal Maxambomba. Através das atividades realizadas na escola tais problemas foram contextualizados por meio da exposição e discussão de notícias de jornais que mostravam a realidade local. Além dos jornais também foi realizado uma análise do Lugar, onde os estudantes identificaram os principais problemas locais e propuseram possíveis soluções.

Após a realização de todas as atividades pode-se perceber que o problema do descarte irregular do lixo em ruas e corpos d'água, entupindo galerias pluviais, poluindo os rios e contribuindo para o assoreamento do rio, foi um dos assuntos bem latentes. Como soluções os estudantes priorizaram a coleta seletiva do lixo, que deveria ser realizada pela prefeitura em todos os bairros do município, independente da classe social e do poder econômico da população local.

O desmatamento e a falta de áreas verdes também foi um assunto recorrente. Apontaram a degradação da mata ciliar como um dos principais problemas, sendo o reflorestamento e a criação de áreas verdes no bairro como soluções para aumentar o lazer da comunidade, minimizar o calor e a ocorrência das enchentes. O lançamento de esgoto doméstico e industrial sem tratamento nos rios está diretamente relacionado com a poluição dos rios e com a proliferação de doenças. Estas que são adquiridas pela ingestão de água contaminada e/ou transmitidas por vetores como mosquitos e ratos, sendo o saneamento básico a melhor forma de resolver este problema.

Uma situação muito importante apontada pelos estudantes diz respeito à visão que a sociedade possui acerca dos problemas socioambientais. É comum a declaração de vários estudantes sobre a falta do senso de coletividade da sociedade, com o crescente aumento do individualismo, fomentando a negligência e a falta de prioridade para a resolução de assuntos da comunidade. Porém, os mesmos afirmam que essa situação precisa ser modificada, pois o meio ambiente é um bem coletivo, onde todos possuem o direito de viver em um ambiente preservado e todos também tem o dever de recuperá-lo.

Enfim, os problemas hidrológicos são uma construção histórica na Baixada Fluminense, que é nos dias atuais, ainda muito presente no cotidiano da população do bairro Engenho Pequeno. Como forma de disseminar estes conhecimentos, o estudo de tais problemas socioambientais a partir do ensino de Geografia, explorando o conceito de lugar, possibilitou que os assuntos ensinados passem a ter significado para os estudantes, estimulando o desenvolvimento da autonomia de cada um, realizando um aprendizado crítico e reflexivo, respeitando as suas limitações e o tempo de aprendizado de cada estudante.

\section{AGRADECIMENTOS}

Agradeço a Coordenação de Aperfeiçoamento de Pessoal de Nível Superior - CAPES pela bolsa de pesquisa concedida, que possibilitou a realização da pesquisa de Mestrado. Gerando como um de seus resultados o presente artigo.

\section{REFERÊNCIAS}

JÚNIOR OSCAR, Antonio Carlos da Silva. A paisagem da Baixada Fluminense: uma análise na perspectiva geoecológica. Revista Brasileira de Geografia Física. número 2, volume 6, Universidade Federal de Pernambuco, Recife, 2013.

BOTELHO, Rosângela Garrido Machado. Bacias Hidrográficas Urbanas. In Geomorfologia Urbana. GUERRA, Antônio José Teixeira (org). Rio de Janeiro, editora Bertrand Brasil, 2011.

TOMINAGA, Lídia Keiko. SANTORO, Jair. AMARAL, Rosangela do (orgs). Cadernos de Educação Ambiental - Desastres Naturais, conhecer para prevenir. Instituto Geológico. São Paulo, 2009

SUERTEGARAY, Dirce Maria Antunes. Geografia e interdisciplinaridade. Espaço geográfico: interface natureza e sociedade. Revista Geosul, número 35, volume 18 , Florianópolis, 2003.

TAVARES, Felipe Rangel. $O$ cinza que se expande pelo verde que se vende: geração de estratégias através de condições na Baixada Fluminense - RJ. Anais do XVI Encontro Nacional de Geógrafos, Porto Alegre, 2010.

\begin{tabular}{llllll}
\hline Caminhos de Geografia & Uberlândia - MG & v. 19, n. 68 & Dez/2018 & p. 116-131 & Página 130
\end{tabular}


GUERRA, Antônio José Teixeira. Novo dicionário Geológico-Geomorfológico, $6^{a}$ edição, Rio de Janeiro: Editora Bertrand Brasil, 2008.

ROCHA, André Santos da. Projetos e intervenções de saneamento na Baixada Fluminense do século XIX e início do século XX - representações e continuidades. Revista Continentes, ano 3 , número 5, Universidade Federal Rural do Rio de Janeiro - UFRRJ, Seropédica, 2014.

SIMÕES, Manuel Ricardo. A cidade estilhaçada: reestruturação econômica e emancipações municipais na Baixada Fluminense. Tese de Doutorado do Programa de Pósgraduação em Geografia, Universidade Federal Fluminense - UFF, Niterói, 2006.

AMADOR, E.S. Baia de Guanabara e Ecossistemas Periféricos: Homem e Natureza. Rio de Janeiro: Reproarte, 1997, 539p.

ABREU, Marcelle. Nova Iguaçu se previne contra as enchentes de verão. Site da Baixada Notícias, 13 de dezembro de 2010. Acesso em 14 de junho de 2016.

AMADO, Aécio. CREA visita pontos críticos de enchentes no Rio. Empresa Brasileira de Comunicação - EBC, 19 de dezembro de 2013. Acesso em 14 de junho de 2016.

CAMARA, Wandemberg. Bornier passa o fim de semana inspecionando obras na cidade e ouvindo lideranças religiosas. Jornal Folha do Iguassú, 20 de outubro de 2015. Acesso em 14 de junho de 2016.

CAMARA, Wandemberg. Nova Iguaçu tem 1.100 desabrigados e desalojados em 26 regiões da cidade. Jornal Folha do Iguassú, 12 de outubro de 2013. Acesso em 14 de junho de 2016.

CAMARA, Wandemberg. Prefeitura começa a dragar afluente do Rio Botas. Jornal Folha do Iguassú, 29 de novembro de 2013. Acesso em 14 de junho de 2016.

Portal G1. Nova Iguaçu organiza força-tarefa para combater enchentes. Rede de Televisão

Globo, 30 de novembro de 2006. Acesso em 14 de junho de 2016.

Recebido em: 30/10/2017

Aceito para publicação em: 23/05/2018 